\title{
Study on the Rational Use of a Rural Middle School Sports Venues and Sports Equipment Resources
}

\author{
Xinyu $\mathrm{Li}^{*}$
}

Institute of Physical Education, Yangtze University, jingzhou 434023, Hubei, China

\begin{abstract}
In recent years, with the rise of the national economy, continue to enrich and perfect teaching system, school physical education is to get the attention of society and school, and achieved certain results, but in the undeveloped or underdeveloped areas, school physical education and health education present situation is not optimistic, which is the basic material conditions of sports equipment resources there is a direct relationship between the not perfect. This research is based on a rural middle school sports equipment resources the development and present situation of research, the current situation of middle school sports equipment resources investigation and statistical analysis, find out the defects existing in the middle school and the school sports equipment shortage, put forward the corresponding countermeasures, and provide a theoretical basis for the less developed areas of school physical education and health curriculum to create a good teaching conditions. This article uses the literature material law, questionnaire survey method, mathematical statistics method, field survey method and other research methods, research status of sports equipment resources of the stratified random sample of middle school and its development and utilization. Then, aiming at the problems found in the study, and puts forward some suggestions: school leaders should strengthen the school sports venues and equipment seriously, and strive to reach the national standard, strengthen the school sports venues, equipment and other infrastructure construction of curriculum resources; school physical education teachers should improve the basic skills, not only to the "special" and "Bo"; the school should strengthen the equipment management system, and reasonable arrangements for the allocation of facilities and equipment; encourage teachers to improve their own abilities, the cultivation of creative thinking, reform and innovation by using the existing facilities organized PE teaching; make full use of existing facilities, reasonable layout of schools, the school environment, climate, cultural characteristics actively explore the school around the site, combined with the actual situation of the school to organize the sports teaching.
\end{abstract}

Keywords: İnvestigation on the current situation and development, rural middle schools, sports field equipment.

\section{INTRODUCTION}

The middle of the twentieth Century, most of the countries all over the world are facing the same question: middle and primary school sports equipment and facilities inadequate. In order to have the system, effectively solve this problem, improve the attention of many countries in the construction of sports facilities, a relatively high proportion of investment. In Japan, the Japanese government since 1959, there are a lot of money into the construction of the school sports equipment every year. Japan more than $90 \%$ of the school has a gymnasium, stadium, swimming pool and other sports facilities; since 1970, the construction of primary and secondary schools in Denmark sports equipment investment proportion, sports hall in Denmark every school has a $40 \mathrm{~m} *$ $20 \mathrm{~m}$; in Austria and other countries, the domestic big city construction of large-scale outdoor sports facilities in schools, supply. In 2005, Sun Zhongchun proposed [1-5] in the investigation on the current situation of foreign sports equipment: foreign government attaches great importance to the construction of sports venues and equipment, not only issued a decree, force local governments to intensify the construction of sports venues and pay attention to the operation and management of venues. At the same time, increase the number of sports facilities in the community sports activities, calling for more people to participate in sports. In Finland, requires every primary school at least a formal ball games and track and field site. In Norway, each school has a gymnasium is required. Peru state in the promulgation of the "sports law" [6-8] clear: the construction of sports facilities for the construction of various facilities planning in the proportion of $50 \%$, all the schools in the country, stipulated the construction must have sports facilities. In 2008 Tang Xun, Jean health [9-11] described in the research on the construction of sports facilities in the foreign department of the British government to strengthen the construction of sports equipment and facilities, will be an additional 100000000 pounds of various kinds of sports schools, at the same time the school should be based on the number of students is much less to make the same scale of sports venues. Literature, sports equipment resources at home and abroad mainly aims at the stadium operation and management, the construction of schools in Sweden, the stadium is set according to the physical and mental development of students, between the different study section of the stadium is not the same size, infrastructure should be equipped with stadium with the school, such as classrooms, students the locker room. "This 
article" Sports Teaching Journal [12] description of the American sports facilities: the construction of sports venues America is quite common, not only in the study of stadiums in the community, and also the construction of stadiums, venues with each rate is very high, almost to the point of supply. In Germany, the government not only provides a good sports stadium, also set the "three gold plan" in order to better public participation in sports and fitness activities. Through the literature review the author learned that, due to differences in the world of politics, economy, culture, urban and rural population structure, mode of production is not the same, the school sports teaching, extracurricular sports activities and sports to carry out extensive, school sports equipment facilities can meet the above activities. Still does not see more in the development and utilization of school sports venues and equipment.

\section{AN OVERVIEW OF THE RESEARCH METHODS USED IN THIS PAPER}

The authors of this paper mainly include: literature method, questionnaire survey method, field survey method, method of mathematical statistics and logical analysis etc..

\subsection{The Investigation Method of Literature}

According to the research objectives and content, through access to a library, Jishou University library, China CNKI database, the library of College of physical science, the Internet access to relevant literature text data, access to the school of sports science, sociology, psychology, educational laws and regulations and the relevant documents, regulations, school sports and the research the Yearbook class books, periodicals, etc.; secondly, through the Jishou University library network has purchased cyber source database, access to domestic and foreign about the school sports equipment and facilities at present, the research achievements of development and utilization of sports equipment, through the discussion and study of previous studies, to understand and summarize, get a lot of useful inspiration, help the scientific reference and theoretical research perspective, their methods, research process and unique point of view for the research of this article.

\subsection{The Investigation Method of the Questionnaire}

In this paper, questionnaire survey to determine the time in the 9-10 month 2012 two months, in the questionnaire before the holiday, the opportunity to give me help questionnaire, personnel training system, to ensure that their questionnaire distribution and recovery work after the thorough investigation and Research on the object of investigation. The questionnaire survey as the set is divided into two parts, namely the teacher questionnaire and student questionnaire, teacher questionnaire is personally visited the investigation of the school's physical education teacher and ask them to fill in the questionnaire on the spot on the spot and recycling, recycling the questionnaire was $100 \%$, the effective number of copies of the inspection questionnaire, efficiency $100 \%$. The questionnaire is a questionnaire to survey the school from the class to ask the teacher in charge to assist the unified survey, questionnaire and on the spot recovery, issued a total of 500 student questionnaires, 494 were recovered, re- covery rate of $98.80 \%$, the test excluding 4 invalid questionnaires effective rate was $99.19 \%$. The senior high school students 80 copies of questionnaires, 78 copies of valid questionnaires; junior middle school students, 415 copies of questionnaires, 412 valid questionnaires (see Table 1).

Table 1. The statistics of a current situation of middle school sports equipment resources survey questionnaire $(\mathbf{n}=\mathbf{5 5 0})$.

\begin{tabular}{|c|c|c|c|}
\hline & Teacher & Student & Total \\
\hline \hline The questionnaire & 50 & 500 & 550 \\
\hline $\begin{array}{c}\text { Recovery of the } \\
\text { questionnaire }\end{array}$ & 50 & 494 & 544 \\
\hline The recovery rate (\%) & 100.00 & 98.80 & 98.91 \\
\hline $\begin{array}{c}\text { The effective question- } \\
\text { naire }\end{array}$ & 50 & 490 & 540 \\
\hline Efficiency (\%) & 100.00 & 99.19 & 99.26 \\
\hline
\end{tabular}

The validity of the questionnaire: the validity of the questionnaire by using expert evaluation method, the main evaluation in two aspects of the structure and content of the questionnaire. Please research experts and the questionnaire survey to design indicators of the effectiveness evaluation and proposes improvement (see Appendix B). Evaluation index design and survey questionnaire asked 8 experts for the evaluation of the construct validity of the questionnaire, the 8 experts, to achieve a better ratio of $100 \%$, good content validity and above the proportion of $87.5 \%$, in line with the requirements of validity test (see Table 2 ).

To test reliability of the questionnaire survey on the object of study: in the whole 15 days later, on the research object of the teachers, the students selected from 20 randomly selected 100 students using the same questionnaire survey again, after analysis and calculation two times before and after the adjustment of the correlation coefficient of $\mathrm{R}$ teachers $r$ students $=0.835>0.8 ;=0.847>0.8, \mathrm{P}<0.01$ shows the reliability of the questionnaire in full compliance with the requirements of the investigation.

\subsection{The Field Survey Method}

According to the needs of the content and objectives of the study, in a month's time field visits to investigate part of rural middle school. Emphatically investigates the situation of school sports equipment resources, near the school environment, school sports equipment and the development and utilization of PE teachers, using the existing equipment resources to organize the teaching situation, the access, in the form of discussion with some students, teachers and school leaders in charge of communication, record, access to research contents needed the first hand data.

\subsection{Mathematical Statistics Method}

In this paper to study the problem, the collected data classification, sorting. By using Excel2007, SPSS17.0 software was used for statistical processing of the valid 
Table 2. The statistics of a current situation of middle school sports equipment resources questionnaire validity evaluation results $(\mathrm{N}=\mathbf{8})$.

\begin{tabular}{|c|c|c|c|c|c|c|c|c|c|c|}
\hline \multirow{2}{*}{ The Evaluation Content } & \multicolumn{2}{|c|}{ Excellent } & \multicolumn{2}{|c|}{ Good } & \multicolumn{2}{|c|}{ Pass } & \multicolumn{2}{|c|}{$\begin{array}{l}\text { Not Up to the } \\
\text { Standard }\end{array}$} & \multicolumn{2}{|c|}{ Very Poor } \\
\hline & $\mathbf{n}$ & $\%$ & $\mathbf{n}$ & $\%$ & $\mathbf{n}$ & $\%$ & $\mathbf{n}$ & $\%$ & $\mathbf{n}$ & $\%$ \\
\hline Structure validity & 5 & 62.50 & 3 & 37.50 & 0 & 0.00 & 0 & 0.00 & 0 & 0.00 \\
\hline Content validity & 5 & 62.50 & 2 & 25.00 & 1 & 12.50 & 0 & 0.00 & 0 & 0.00 \\
\hline
\end{tabular}

questionnaires, results are expressed as percentages. Qualitative analysis was based on a quantitative basis, and with the "school sports equipment and facilities equipped with the national standard" directory comparison, provide systematic, complete, accurate data for the research needs, to ensure the scientific research.

\subsection{The Logic Analysis Method}

On the basis of consulting a large number of relevant data, through the use of analogy, deduction, induction, analysis, reasoning and logic analysis method; combination of sports sociology, sports management, sports psychology and other disciplines of sports theory, the material is a rural middle school sports information with the case analysis, the paper concludes the right.

\section{THE RESULTS AND ANALYSIS}

Comprehensive promotion of quality education, let the students all-round development is China's current education system, but most of the schools to improve school enrollment rate, large amount of resources invested in the education teaching work, but ignore the physical exercise. "Sunshine Sports" promulgated, that physical exercise on physical and mental health of primary and middle school students the importance of. Most of the school is only limited to the discipline construction in cultural studies, for the construction of sports and health of the subject completely ignored, not only does not have special money, and even the government departments into the sports education special funds have also been used for other purposes, to a large extent, the only sports equipment and facilities are not to improve or add, not only affects the school physical education activities, and even affect the physical and mental health of students.

\subsection{The Number of Sports Facilities}

The role of sports equipment and sports played as important, is the basic way to realize the education guiding ideology of "health first" effective, sports equipment is the fundamental guarantee to the sports teaching activities carried out smoothly, to standardize the school condition is also launched the first sports teaching. According to the 2005 state of equipment and facilities equipped with the standard of "school site equipment directory", according to the local actual situation, the author of a rural middle school sports equipment and facilities equipped with the investigation, the results of the survey are shown in Fig. (1).

National standards for equipment classification, mainly in the class, must be equipped with optional class, the class must be equipped with the standard is mainly based on sports and health course planning for school sports equipment equipment must be equipped with. Selection is not fully specified must be equipped with such devices, is on the basis of the economic situation, the teaching goal, teaching content and the actual situation with a school-based curriculum, most schools, for equipment selection, can be equipped according to the school.

Fig. (1) shows: a rural middle school in the school sports equipment and facilities equipped with respect to the national standard is low, in the investigation of the school, senior high school to achieve a national with the ratio of $75 \%$, while only $59.20 \%$ of primary school. The two class is a class of fully equipped with the premise of rural area, most of the economy is not well-off, the leadership is not enough attention to add and management of sports equipment, to achieve high school state class two is equipped with a proportion of $25 \%, 40.48 \%$ primary schools with the most basic category can't reach, let alone reached two with class requirements.

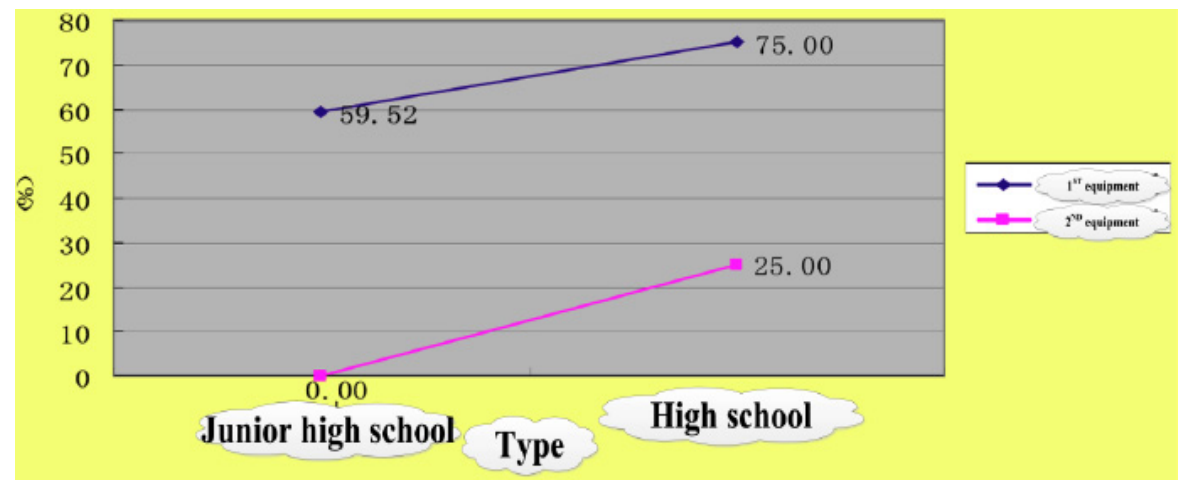

Fig. (1). Equipped with a drawing of a middle school sports facilities. 


\subsection{The Quality of Sports Equipment and Facilities}

For the quality of sports equipment, the national standard does not require a high school sports equipment quality problem, in view of this problem, the author access relevant documents / files are learned, in Shanxi, Fujian, Jiangsu Province as an example, the senior high school equipment quality standards should be nine years compulsory standards for the implementation of at present, Henan province for equipment quality is not clearly defined, so the author combined with the actual situation of the national standards and local high school for local high school sports quality survey, aimed at a comprehensive understanding of the local school leaders pay more attention to the sports teaching activities and sports facilities in investment. Mainly uses the questionnaire survey and field investigation, the way to obtain the effective data.

Through the investigation of the local rural secondary school leaders and sports teachers, the author selected three important indexes to make a brief description of research content, understanding degree indicators include sports equipment, sports equipment procurement mode of national standard and school self evaluation of equipment. The results of the survey are as follows (see Table 3).

Survey: school buy sports equipment mainly uses two kinds of bidding and bargaining, the local rural middle school sports facilities for the purchase, the purchase of equipment is the traditional way of bargaining accounted for $62 \%$, for the more modern bidding, the proportion was only $38 \%$, the local rural areas, thinking is more conservative and the economy well, for the purchase of equipment, most believed that only the most conservative is the best way to buy. Procurement of junior high school than senior high school, senior high school of $75 \%$ commonly used forms to buy bargain purchase of sports equipment and facilities.

50 schools in the survey, most of the State responsible for sports equipment equipped with the standard awareness is not high, only $30 \%$ of standard are familiar with, but in that familiar with the thorough understanding of the edge, $70 \%$ of people are not familiar with the content, the serious problem. The high school and middle school are not familiar with, the proportion was $62.50 \%$ and $71.43 \%$, the survey data shows, the local rural areas for the national stan- dard of school sports equipment with awareness is not high, and the quantity and quality of sports equipment can not reach the national standard.

The school equipment quality self-evaluation, evaluation of "excellent" and "poor" level of the ratio is not high, the total proportion of $36 \%$, which accounted for $18 \%$ of "good", "bad" accounted for $18 \%$. 64\% of the person in charge of the school is not particularly high requirements for the quality of equipment, the school sports equipment is good, no need to update or improve. The school sports equipment self-evaluation, reflected from the side of sports equipment in rural middle school is equipped with a number of local and national quality standards, there is a certain distance. As the first junior high school sports equipment due to the lack of timely updates, sports equipment such as basketball school, parallel bars, horizontal bar and other equipment for year-round use appear aging phenomenon seriously, for this, school leaders did not cause much attention. The main reason is the school funds is limited, for the construction of sports equipment can't be timely updated.

\section{THE DEVELOPMENT OF SPORTS FACILITIES RESOURCES AND OPTIMIZATION METHOD}

Strengthen the quality of education, the students' physical and mental health, enhance the students' physical health and the implementation of the "health first" guiding ideology of school physical education cannot do without. However, sports equipment and facilities to ensure the physical education is indispensable material. Lack of sports venues and equipment seriously affects the school sports activities, under the limited economic conditions and the lack of venues and equipment situation, only the development and utilization of sports venues and equipment available. Somewhere in the area, most of the limited economic conditions in rural areas, the school playground equipment resources serious shortage, in order to meet the needs of rural middle school students in daily teaching activities, under the shortage of resources to play itself has facilities and the role of the development of the potential function is necessary, through the school equipment management, the author attempts to explore the research from the following several aspects [12].

Table 3. Analysis of school sports equipment and facilities quality questionnaire ( $\mathbf{N}=\mathbf{5 0})$.

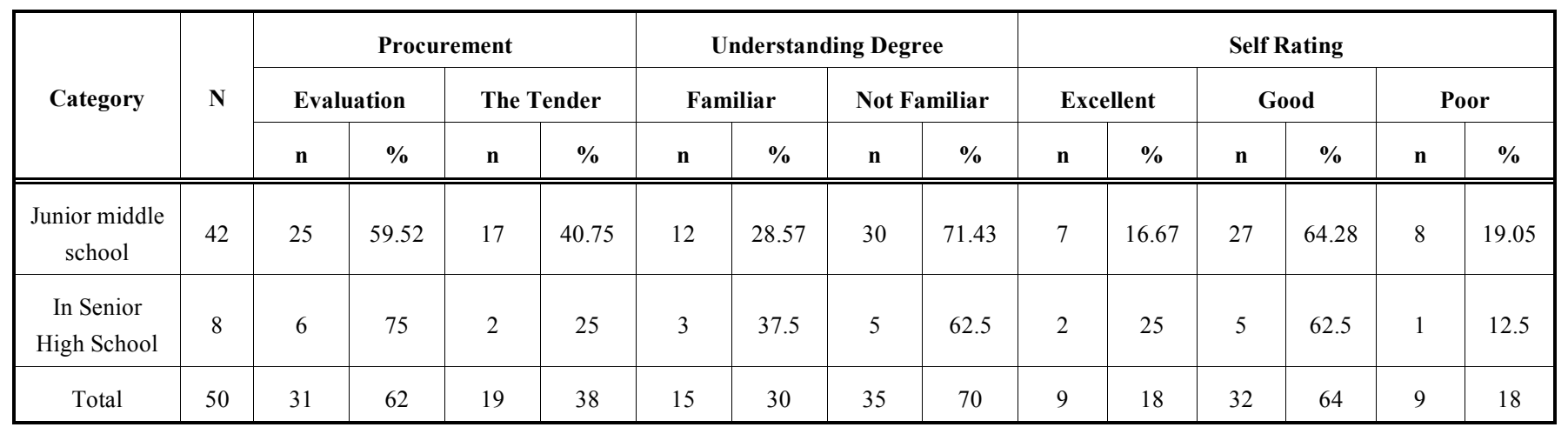




\subsection{Give Full Play to the Multiple Functions of Sports Equipment}

On the basis of a rural middle school sports equipment available, the sports equipment with multiple function is a relatively convenient and easy to implement the effective ways to improve the school sports facilities lack. Sports equipment generally has multiple functions, only need a variety of new features we have to think differently about the sports equipment and the development of commonly used sports equipment. For example: not only for javelin throwing, but also can be used as markers and football round bar; usually used in hurdle race [13], we can also use the as cast shot or obstacles; shot is throwing equipment, but can be used as weights, markers, obstacle avoidance, but also can be used as a new project introduction bowling; skipping rope can't only, also can be used as a pull rope, three wrestling, throwing, jumping rope clip, string, rope moving, snake, two run throwing rope three feet running, step on the tail; the rubber band can be used as the high jump with the horizontal pole etc..

\subsection{Simple Production Equipment}

Through the use of waste or simple things, give full play to the students' imagination and creativity to produce suitable for sports teaching relatively simple sports equipment. Create a simple equipment can not only relieve the loss caused by the equipment of physical education teaching activities, but also save money. Related to the leadership of a rural middle school physical education teachers should actively mobilize students and sports equipment, simple production. For example: the teachers ask the students to do it yourself using the waste beverage bottles, making simple projectiles, markers, obstacles and small dumbbell; out of old cloth and sand or beans from the simple bag making rope; cane; utilization of the door as a table tennis activities [14]; make obstacles or mark by using straw; small steps on campus as an exercise balance beam; utilization of waste tires as lifting; can also be used as a school for students to use the stump jump. At the same time, the organization of sports teachers and students combined with local conditions, give full play to creativity and imagination, the use of limited resources, the creation of sports equipment for schools for teaching activities more or extracurricular sports activities. Teachers can use sticks to make a baton baton, and can be done with a baton, which can be used for sports games, but also as a marker placed "runway" let the student carry on running and jumping exercises. As long as we are good at thinking and change the way of thinking, simple production equipment utilization of waste items, one thing and play equipment with multiple functions. Through the sports equipment simple, not only can cultivate students' ability to use your hands, more so that they can understand the characteristics and contents of the sports project, to their mastery of teaching content and achieve the goal of physical education teaching. In the selfmade equipment in the process, students' emulative heart is strong, in order to get recognized by the teachers and other students, give full play the main role of its own and creativity, not only the students' divergent thinking, but also to strengthen the students' practical ability. In the sports class, students not only improve the protection consciousness of sports equipment, and improve the enthusiasm of the stu- dents. Through the homemade sports equipment, on the one hand, due to the lack of sports equipment can alleviate the pressure brought to the sports teaching activities, on the other hand can save money, provide good material basis for equipment renewal.

\subsection{Transformation Equipment, Improve Space Utiliza- tion Value}

The construction of sports equipment in rural middle school is mainly based on the competitive sports venues for the standard limit of middle school students, sports, the school should take the student as the main body, in the construction of school facilities to students interested in the actual situation and the movement as the basis, the adult of transformation of the existing school facilities suitable for middle school students activity venues and equipment, improve the enthusiasm of students to participate in activities. The transformation of school facilities, should be based on students' interests, the reasonable transformation of the equipment, while meeting the needs of physical education teaching and improve students' interest in sports activities. For example: on the basketball court, appropriate to reduce the height of the basketball, basketball court, volleyball net reduction to reduce the height of building, the tug of war competition, play games, activities and other activities can be free area.

\subsection{Rational Layout of the School Facilities and Equip- ment}

In the campus environment, rational layout, display school sports venues and sports equipment position arrangement, is a simple and effective way to solve the shortage of sports equipment seriously affects the school sports activities. The sports venue layout to suit one's measures to local conditions, tailored, set the appropriate facilities and equipment. In the survey found that the transformation of schools, sports equipment work crunch time, school sports teaching activities and students' training and extracurricular activities need not satisfy. The school has enough space to meet the students' sports activities, to ensure the safety of teachers and more. Through the reasonable layout of reasonable layout and equipment of the school grounds, at the same time, the effective use of idle land to the school, not only to meet the basic activities of sports teaching, also can be introduced in line with the actual situation of the school sports and meet the students' physical and mental development. For schools around the geographical environment, the school should be appropriate to use, favorable geographic environment of campus sports venues and the fully integrated, so that the local rural middle school based on the most incisive in the limited financial resources on the function of sports equipment.

\subsection{The Rational Use of Space and Equipment}

The use of sports facilities, the first is to reasonable treatment, and stressed that the site equipment use is appropriate, whether to maximize its own value, whether to use after considering its management and maintenance etc.. Secondly to make arrangements to maximize the use of sports venues and equipment Business Hours, rational overall ar- 
rangement of curriculum by the Secretary to be reflected, if limited teaching conditions, can't be guaranteed, can according to the surrounding environment of the school, the local cultural customs, fully tap the use of school sports venues and equipment and the use of space, teaching such as the use of the surrounding mountain climbing, cross-country running students etc.. Also note that the final implementation of the school sports equipment maintenance and maintenance work, ensure the sports equipment resources Limited have infinite circulation, eliminate waste.

\section{RELEVANT SUGGESTIONS}

Sports in rural middle school to the high school with the overall level is higher than the junior middle school, but the overall level is not high, coupled with a number of rural middle school class were higher than the standard classes, with a number of more than site. The basketball court with quantity can meet the standard completely, but the site quality failed to meet the national standard requirements; the number of track and field, volleyball court with the relative shortage of part of the junior high school failed to meet minimum standards, site quality is not up to the requirements of the national standard, still need to be further improved. The number of sports equipment in rural middle school is equipped with respect to the requirements of national standard equipment, there is a certain gap with equipment, there are also differences in sports, basketball, track and field, volleyball compared with sports equipment must be high, some necessary equipment in the local rural middle school did not reflect.

Sports equipment in rural middle school management there is a big problem, not only did not establish corresponding management system, in the development of management system for equipment management in school, never by his. Equipment management is not responsible for their own work, do things carelessly, on site equipment management is "open eyes closed eyes,", did not do due diligence. Lack of sports venues and equipment, has brought some adverse effects on the teaching activities of school physical education, not only the lack of teachers and students actively in class, but also the lack of sport. School physical education and health course teaching objectives, curriculum setting and teaching forms of organization are not up to the standard of the new curriculum reform. The main part of rural middle school in the number of school facilities are still inadequate, the quality of each school is different, the local rural school site equipment is not according to the new requirements of the national standard equipment. A rural middle school site equipment management needs to be further improved in areas such as the lack of. Most of the schools in a rural middle school in the development and utilization of sports venues and equipment available, can meet the basic needs of the school sports teaching, in order to better implement the quality education better in China's rural areas, the school should not only in the construction of sports facilities and the proportion of investment, but also need to call the school teachers and students in the development and utilization of school sports equipment on existing put forward good ideas.

The school leaders attach great importance to the important role of physical education in middle school education, to avoid the impact of the current system of education and examination oriented education while ignoring the importance of school physical education, the sports education funds for other purposes only, do not pay attention to the construction of the school sports equipment. Make full use of school sports education special funds venue equipment update, the school grounds equipment can basically reach the national standard of middle school site equipment. Physical education teachers should be the comprehensive development, should master the basic knowledge and basic skills of the subject. Must not only be "designed" and "Bo". In strengthening the personal skills at the same time, but also to strengthen the cultivation of professional theory knowledge, make the comprehensive development of students, to fully understand the subject and actively participate in sports activities.

The school should strengthen the management of venues and equipment, especially the equipment administrator, should set up a clear system of rewards and penalties on it, so that it does not work in the passive treatment, strengthen the equipment management and maintenance work every day. The school sports curriculum should develop a reasonable, scientific, in principle, only the first class in the morning class time is not arranged by time and space, the maximum limit, completely change the past five or six classes and class cause site crowded phenomenon. According to the principle of individualized instruction, according to the students' interest in sports classification arrangement of sports venues, the grade, the students can be natural sites without mutual interference in sports activities. To strengthen the development and utilization of the facilities and equipment, to improve the students' divergent thinking, make the equipment to play a "multi-purpose" function, and use their brains, simple production equipment for the sports teaching the use of waste materials and daily necessities. At the same time to strengthen the rural middle school sports teachers' personal comprehensive quality training, improve the teachers' ability of creative thinking, to relieve pressure in the process of physical education teaching.

\section{CONCLUSION}

Based on the known conditions, the local rural human environment and so on, to understand the current situation of middle school sports equipment resources in rural areas. Through the investigation, research and development of current situation on site equipment resources in rural middle school in the area, the economy in the rural areas in relatively backward, according to the local environment and natural geography environment for the development of ground equipment requirements low and suitable for middle school students to carry out the local sports, sports equipment is reduced due to lack of resources for sports activities.

Due to the need of research objectives and content, design the questionnaire topic more, data processing is complex, the survey time span, coupled with the impact of economic factors, school location, can't be timely and accurate access to first-hand information, reflect the current situation of rural middle school sports venues and equipment resources.

In this paper, the development and utilization of a rural middle school site analysis is not comprehensive enough, 
only part of the site or equipment for the development and utilization, therefore, the future research needs to be done to throw the correlation analysis, a full range of deep in the rural middle school, and provide reference for reasonable and make full use of the space equipment resource organization of physical exercise.

\section{CONFLICT OF INTEREST}

The author confirms that this article content has no conflict of interest.

\section{ACKNOWLEDGEMENTS}

Declared none.

\section{REFERENCES}

[1] C.R. Burgeson, H. Wechsler, N.D. Brener, J.C. Young, and C.G. Spain, "Physical education and activity: results from the School Health Policies and Programs Study 2000," The Journal of School Health, vol. 71, no. 7, pp. 279, 2001.

[2] R.T. Enander, D.M. Gute, H.J. Cohen, L.C. Brown, A.M.C. Desmaris, and R. Missaghian, "Chemical characterization of sanding dust and methylene chloride usage in automotive refinishing: implications for occupational and environmental health," AIHA Journal, vol. 63, no. 6, pp. 741-749, 2002.

[3] "Compiling group of sports equipment and facilities in primary and secondary schools," The School Sports Equipment and Venues (National Standard) GB/T19851, 4-2005. (in Chinese)
[4] "Beijing: Chinese National Standardization Management Committee," 2005. (in Chinese)

[5] "The middle school sports equipment and facilities equipped with the directory," Ministry of Education, 2005. (in Chinese)

[6] M. Nestle, and M.F. Jacobson, "Halting the obesity epidemic: a public health policy approach," Public Health Reports, vol. 115, no. 1 , pp. 12, 2000.

[7] J. Marshall, and K. Hardman, "The state and status of physical education in schools in international context," European Physical Education Review, vol. 6, no. 3, pp. 203-229, 2000.

[8] Y. Han, and P. Lu, "Sports equipment in primary and middle schools in Gansu province," Journal of Heilongjiang Vocational Institute of Ecological Engineering, vol. 9, 2009. (in Chinese)

[9] W. Jing, "Present Situation and Corresponding Solutions to Opening the sports facilities of the promary and middle schools to the public,"Fujian Sports Science and Technology, vol. 2, no. 2, pp. 51-53, 2003.

[10] Y. SHAO, "Research on the Creation, Development, and Fitness Function of Yangge," Journal of Beijing Sport University, vol. 11, no. 11 , pp. $1485-1487,2006$

[11] B. Houlihan,"Sporting excellence, schools and sports development: The politics of crowded policy spaces," European Physical Education Review, vol. 6, no. 2, pp. 171-193, 2000.

[12] U. Hannerz, "The world in creolisation, "Africa, vol. 57, no. 4, pp. 546-559, 1987.

[13] X. Tang, and J. Jean "Abroad school sports facilities and open review," Shandong Sports Science and Technology, vol. 30, no. 1, 2008.

[14] M. Wisniewski, "Using SERVQUAL to assess customer satisfaction with public sector services," Managing Service Quality: An International Journal, vol. 11, no. 6, pp. 380-388, 2001.

Received: June 10, 2015
(C) Xinyu Li; Licensee Bentham Open.

This is an open access article licensed under the terms of the (https://creativecommons.org/licenses/by/4.0/legalcode), which permits unrestricted, noncommercial use, distribution and reproduction in any medium, provided the work is properly cited. 